\title{
ANÁLISE DE PERDAS E MELHORIAS BASEADAS EM CONCEITOS DE PRODUÇÃO ENXUTA NA INDÚSTRIA VINÍCOLA
}

\section{LOSS AND IMPROVEMENT ANALYSYS BASED ON LEAN CONCEPTS APPLIED TO THE WINE INDUSTRY}

\author{
Michel José Anzanello ; Antônio Galindo Falcão ${ }^{2}$; Flavio Sanson Fogliatto ${ }^{3}$; Tiago Pascoal \\ Filomena \\ ${ }^{1}$ RUTGERS - The State University of New Jersey - New Jersey - EUA \\ michelja@eden.rutgers.edu \\ ${ }^{2}$ Universidade Federal do Rio Grande do Sul - UFRGS- Porto Alegre -Brasil \\ asergf@uol.com.br \\ ${ }^{3}$ Universidade Federal do Rio Grande do Sul - UFRGS- Porto Alegre -Brasil \\ ffogliatto@producao.ufgrs.br \\ ${ }^{4}$ The George Washington University - Washington DC - EUA \\ tiagopf@gwu.edu
}

\begin{abstract}
Resumo
Nos últimos anos, o setor vinícola nacional vem apresentando diversas transformações em seus processos produtivos. Melhorias focadas na qualidade final do produto, bem como no processo de produção em si, passaram a ser fundamentais à sobrevivência do setor frente ao crescente volume de vinhos importados disponíveis no mercado nacional. De tal forma, perdas no processo produtivo devem ser minimizadas elou eliminadas para assegurar a competitividade do segmento nacional. Este artigo apresenta uma aplicação inédita dos conceitos do Sistema Toyota de Produção (STP) na melhoria do processo produtivo em uma empresa vinícola. No estudo de caso que ilustra o artigo, a linha de engarrafamento foi identificada como concentradora das perdas de produção mais pronunciadas, por intermédio de entrevistas e filmagem dos procedimentos envolvidos. Ferramentas oriundas da Engenharia de Produção, como mudança de layout e desenvolvimento de dispositivos anti-falhas, foram implementadas na linha de engarrafamento. As modificações propostas conduziram à redução do transporte de insumos, eliminação de perdas por ruptura de vasilhame e otimização do número de operários no setor.
\end{abstract}

Palavras-chave: análise de perdas, manufatura enxuta, Sistema Toyota de Produção, indústria vinícola.

\section{Introdução}

O surgimento de um número cada vez maior de empresas dotadas de tecnologia de ponta no ramo vinícola (POMPELLI; PICK, 1999), aliado à crescente importação de vinhos provenientes de 
países com tradição consolidada (ANDERSON, 2004), tem impulsionado vinificadores de menor porte a aprimorarem seus processos no sentido de assegurar qualidade ao vinho e colocá-lo em posição destacada entre as bebidas de consumo habitual. Uma das diretrizes é evitar a perda de competitividade decorrente de gastos que não agregam valor ao produto.

O processo de elaboração de vinho, embora antigo, tem sido foco de elevado número de estudos no sentido de aprimorar suas etapas. Tais estudos concentraram-se, em sua maioria, no controle e otimização dos parâmetros que regem os mecanismos de fermentação (MANCOZZO et al., 1999; NETZEL et al., 2003; OREGLIA, 1964; ZOECKLEIN et al., 1998; BOULTON et al., 1996, entre outros) e no desenvolvimento de técnicas de mensuração da qualidade do produto acabado (ver, por exemplo, TESFAYE et al., 2002; SKOGERSON et al., 2007; VERSARI et al., 2008). Reduzida atenção tem sido dada, no entanto, ao gerenciamento das etapas do processo de produção do vinho; nesse sentido, a abordagem encontrada na literatura prioriza aspectos tecnológicos relacionados às etapas do processo, como em Jonsson e Tragardh (1990), Vemhet et al. (2003) e Salazar et al. (2007). Poucos trabalhos reportam a aplicação de conceitos de Engenharia de Produção na gestão dos processos de produção vinícola; exceções incluem os trabalhos de Orr (1999) e Santo (1996). A adaptação e aplicação dos conceitos de Produção Enxuta, associados ao Sistema Toyota de Produção (STP), à indústria vinícola está ausente da literatura especializada, sendo o principal foco teórico do presente artigo.

Este artigo propõe a utilização de conceitos oriundos do STP em uma empresa do setor vinícola, focando-se na análise de perdas no processo de produção. O objetivo é a identificação de atividades que geram custos e não agregam valor ao produto final. Para tanto, iniciou-se pela identificação do setor com maior impacto de geração de melhorias a partir de uma análise dessa natureza. Utilizando pesquisa qualitativa, através de entrevistas e análise de dados históricos, identificou-se o setor de engarrafamento como responsável pelas maiores perdas produtivas. Em seguida, avaliou-se a execução dos procedimentos relacionados aquele setor sob a ótica do STP, o que possibilitou a identificação das perdas mais pronunciadas. Para cada perda, desenvolveu-se uma solução através da aplicação de ferramentas básicas da Engenharia de Produção, como modificações de layout e desenvolvimento de dispositivos de redução de falhas, entre outros. O estudo aqui reportado foi conduzido em uma empresa de médio porte do ramo vinícola, cuja produção, superior a 3 milhões de litros por ano, é direcionada, em sua maioria, para o mercado consumidor do Rio de Janeiro. A empresa conta com um corpo funcional de quinze operários.

O presente artigo apresenta, como principal contribuição, a adaptação da conceituação de perdas produtivas para processos de produção vinícola. Nesse sentido, é importante enfatizar que grande parte da literatura sobre STP foi desenvolvida em aplicações no setor metal-mecânico, conforme reportados em trabalhos clássicos sobre o assunto, tais como Ohno (1997), Shingo (1985; 
1986; 1996a; 1996b) e Womack et al. (1992). Adaptações conceituais, conforme propostas nesse trabalho, se justificam ao elevar as chances de utilização do STP em outros segmentos industriais afins, o que pode resultar em melhorias de desempenho nesses segmentos e consequente impacto econômico positivo. Contribuições secundárias deste estudo são representadas pelo desenvolvimento de dispositivos operacionais passíveis de adaptação em outros processos de produção de bebidas.

$\mathrm{O}$ artigo está organizado em três seções, além desta introdução. Na seção 2 é apresentado o conceito de perdas e sua classificação, conforme o STP. Na seção 3, descreve-se o processo analisado e apresenta-se um estudo de caso. O artigo é finalizado por uma conclusão, na seção 4 .

\section{Perdas nos Sistemas Produtivos}

Nas décadas de 1970 e 1980, a Toyota Motor Company despontou no cenário mundial como uma das principais montadoras de automóveis. Seu sucesso adveio do desenvolvimento e implementação de um sistema de produção que levou o Japão a um período de grande crescimento econômico, na medida em que outras empresas japonesas adotaram o sistema. Os princípios, conceitos e técnicas de manufatura que estavam por trás do sucesso da Toyota, e do Japão, tornaram-se conhecidos como o Sistema Toyota de Produção - STP, mais conhecido no ocidente, especialmente nos EUA, como Just-in-Time ou Lean Production - Produção Enxuta (WOMACK et al., 1992; ANTUNES, 1998; HOPP; SPEARMAN, 1996).

O STP apresentou-se como um diferencial dentro da concorrência intercapitalista, visto que quebrou importantes tradeoffs existentes desde os primórdios da organização da produção. Esse sistema mostrou que é possível obter variedade de produtos com baixo custo e com qualidade, oferecendo à produção agilidade para mudar seu mix de produção. O sistema facilitou, também, a capacidade de introduzir rapidamente novos produtos no mercado, o que permite o atendimento a pedidos quase personalizados. Tais fatores representam vantagens competitivas.

Os conceitos, princípios e práticas propostos e utilizados no STP são amplamente reconhecidos como elementos constituintes de um modelo robusto de organização e gestão da produção. Dentre os princípios básicos de construção desse modelo, encontra-se o conceito de perdas (ANTUNES, 1998; GHINATO, 1994). O foco na busca e eliminação das perdas produtivas é elemento central na concepção, organização e operacionalização do STP. Sendo o STP um sistema de gerenciamento da produção que tem como objetivo aumentar o lucro através da redução dos custos, faz-se necessário consistentemente identificar e eliminar atividades que não agregam valor ao produto, ou seja, que representam perdas no processo produtivo (GHINATO, 1996).

De acordo com o STP, a capacidade de produção em um sistema produtivo é o resultado da 
soma de trabalho e perdas, conforme a seguinte equação (OHNO, 1997):

\section{Capacidade de Produção $=$ trabalho + perdas}

Trabalho compreende as atividades que levam o processo a efetivamente alcançar seu fim. São de dois tipos: i) Trabalho que adiciona valor; refere-se ao trabalho efetivo, que representa algum tipo de processamento, ou seja, aquilo que agrega valor ao produto e, ii) Trabalho que não adiciona valor, representado por atividades que dão suporte ao processamento propriamente dito (por exemplo, movimentos decorrentes das condições atuais de trabalho que auxiliam a realização do processamento). Perdas, conforme anteriormente, são todas as atividades desnecessárias que geram custos e não agregam valor ao produto e que, portanto, devem ser eliminadas do sistema de produção.

No STP, o aumento da eficiência (ou seja, da capacidade de produção) só pode ser alcançada quando se produz zero perda e eleva-se a porcentagem de trabalho que adiciona valor para $100 \%$. O primeiro passo na busca do aumento da capacidade produtiva, então, consiste na identificação dos tipos de perdas presentes no sistema de manufatura em estudo. No STP são consideradas sete classes de perdas (ANTUNES, 1995; ANTUNES, 1998; OHNO, 1997; SHINGO, 1996a; SHINGO 1996b):

1. Perdas por superprodução: devem ser o principal foco de melhorias nos sistemas produtivos, pois auxiliam a ocultar outras perdas. Podem ser de dois tipos: $i$ ) quantitativa decorrente da produção além da quantidade programada ou necessária, ou por compra de matérias-primas em quantidade maior do que é necessário; ii) por antecipação - decorrente da produção antes do momento necessário; como conseqüência, produtos permanecem estocados aguardando o momento de serem comercializados.

2. Perdas por transporte: decorrentes das atividades de movimentação de materiais, não associadas a qualquer tipo de processamento. No limite, a otimização do processo de transporte leva à eliminação da necessidade de transportar.

3. Perdas no processamento em si: são parcelas do processamento não necessárias para que o produto adquira suas características funcionais.

4. Perdas por fabricação de produtos defeituosos: consistem nas peças, sub-montagens e produtos acabados em desacordo com as especificações de qualidade. Trata-se do tipo de perda mais comum e visível, pois se materializa no objeto da produção, exigindo retrabalho ou refugo do produto. 
5. Perdas por estoque: referem-se aos custos associados à manutenção e movimentação de estoques de matérias-primas, material em processamento e produtos acabados.

6. Perdas por espera: correspondem aos períodos de tempo em que nenhum processo e operação estão sendo executados, embora os custos horários de utilização dos recursos produtivos estejam sendo contabilizados.

7. Perdas por movimentação: referem-se aos movimentos desnecessários executados pelos operadores durante a execução das operações principais. A redução dessas perdas tende a impactar positivamente sobre o tempo total de operação.

Em um dado cenário de análise, as sete perdas descritas acima estão normalmente vinculadas entre si, sendo originárias de disfunções nos processos produtivos (SHINGO, 1996a). Ressalta-se que, na lógica da análise de perdas, apenas o processamento pode agregar valor ao produto. Inspeção, transportes e esperas são perdas. Inspeções, por exemplo, não devem ter o propósito de descobrir defeitos e, sim, de eliminá-los. A necessidade de transportar os objetos de produção, bem como as esperas a que os objetos são submetidos, também devem ser eliminadas ou minimizadas.

Alguns autores propuseram categorias adicionais àquelas listadas na classificação acima. Antunes (1998), por exemplo, propôs a incorporação de perdas ergonômicas e ambientais à análise. $\mathrm{Na}$ prática, categorias adicionais relevantes de perdas podem ser facilmente identificadas pelo analista nos diferentes contextos de aplicação da análise.

\section{Apresentação do caso}

O processo de vinificação é composto por uma série de etapas, as quais compreendem operações sobre a uva e atividades relacionadas aos demais componentes do produto, como garrafa e rótulo. A vinificação tem início com a moagem da uva, a qual é seguida pelo processo de fermentação. Esse processo é responsável pela conversão do açúcar da uva em álcool e demais reações necessárias para a estruturação do vinho. A fermentação é seguida por operações para separação de resíduos do vinho a ser maturado. Após transcorrido o tempo de envelhecimento, o vinho é engarrafado e, posteriormente, encaminhado para comercialização. Paralelamente ao processo de vinificação, garrafas e demais insumos são estocados, sendo utilizados na medida em que são necessitados. É importante enfatizar que a embalagem (garrafa, rótulo, cápsula e rolha) constitui-se em parte do produto final. Tendo-se em vista as exigências dos consumidores em relação ao aspecto visual do produto, aspectos ligados à embalagem têm recebido elevada atenção.

A linha de engarrafamento da empresa em questão utiliza vasilhames com capacidade para 
$750 \mathrm{ml}$. O transporte das garrafas para o início da linha é feito com o auxílio de empilhadeira e a lavagem é manual. Etapas subseqüentes do processo são automatizadas, demandando intervenção dos operários somente no final da linha, onde as garrafas são embaladas em caixotes de papelão. Entretanto, faz-se necessária a inspeção das máquinas pelos operários durante a execução das operações.

As perdas na linha de engarrafamento foram identificadas através de entrevistas com o diretor-técnico da empresa e conversas informais com os encarregados do setor, bem como por intermédio da filmagem dos procedimentos. O funcionamento da linha foi posteriomente analisado para confirmar as deficiências apontadas pelos operadores e estimar a freqüência de ocorrência de falhas nas máquinas. A análise preliminar permitiu identificar as seguintes perdas: $(i)$ estocagem inadequada de vasilhame, (ii) transporte excessivo de materiais, (iii) quebra de vasilhame durante o seu enchimento, e (iv) defeitos na aderência das cápsulas de proteção às garrafas.

A Figura 1 traz o layout antigo da linha de engarrafamento da empresa; o código $\operatorname{OP}_{i}$ ( $i=$ $1, \ldots, 9)$ identifica os operários envolvidos no processo, enquanto que as setas representam o percurso percorrido pelas garrafas durante o processo de engarrafamento. As modificações propostas foram implementadas pela empresa e resultaram no novo layout apresentado na Figura 4.

Figura 1 - Layout antigo da linha de engarrafamento

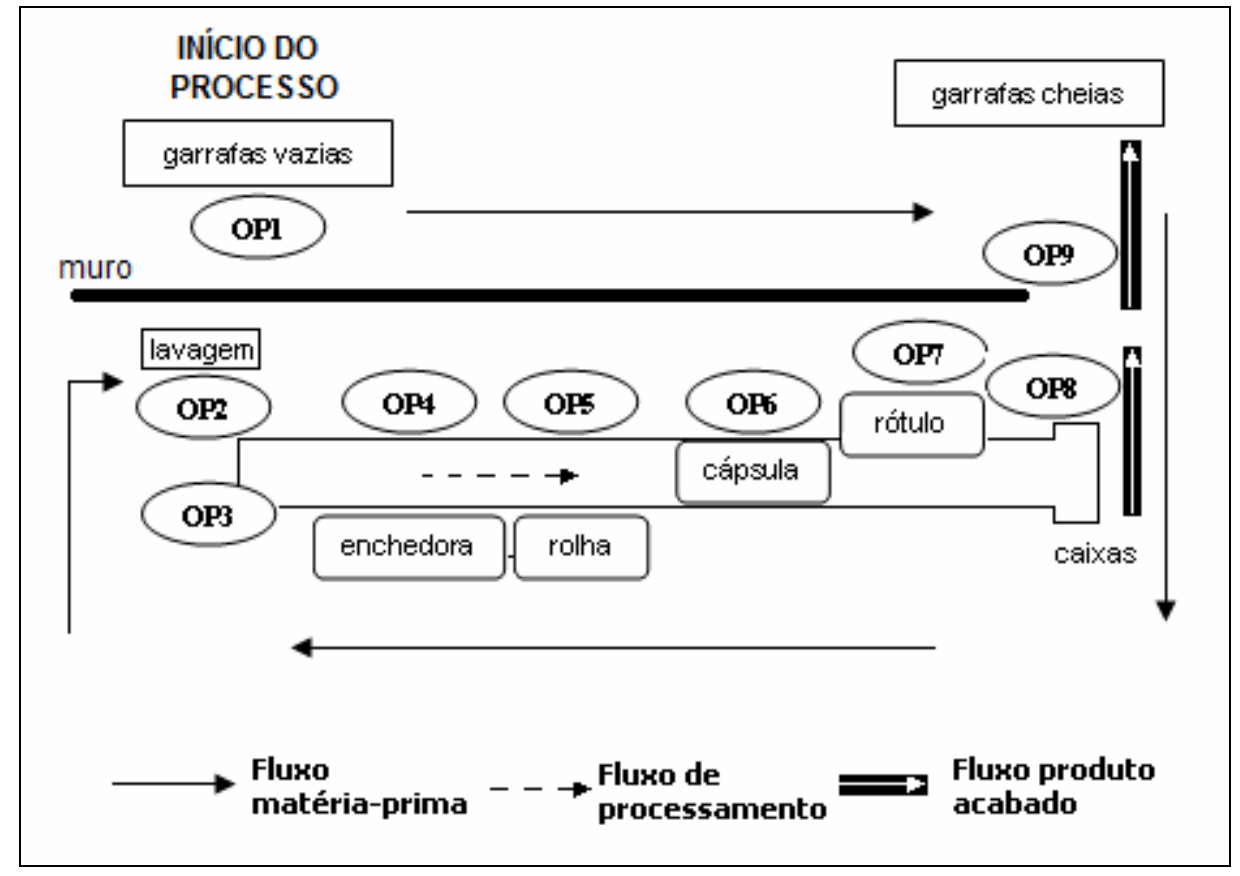

Fonte: Autoria própria (2009)

$\mathrm{Na}$ sequência, são apresentadas as perdas identificadas na análise preliminar do processo e suas prováveis causas. A análise foi utilizada como subsídio para sugestão das modificações implementadas, bem como para elaboração de dispositivos para redução ou eliminação da 
ocorrência das perdas. Esses dispositivos podem ser visualizados nas Figuras 2 e 3. Resultados decorrentes da implantação prática das melhorias são discutidos ao final da análise de cada perda identificada.

\subsection{Perdas por estoque de vasilhames}

Analisando-se a estrutura destinada ao setor de estoques da empresa, pôde-se identificar os seguintes problemas: (1) quantidade excessiva de vasilhames vazios mantidos em estoque (perda por estoque de matéria-prima), (2) posição inadequada do estoque em relação à linha de engarrafamento, gerando transporte excessivo, e (3) grande quantidade de vasilhames cheios aguardando liberação (perda por transporte, decorrente da inadequação do layout produtivo, e por estocagem de produto acabado).

A grande quantidade de vasilhames vazios na empresa [Perda (1)] conduz a perdas por estoque. Além de representar um custo de oportunidade, tal material também difículta a movimentação de empilhadeiras e pessoal, e ocupa um grande espaço físico que poderia ser utilizado para outro fim. O estoque de garrafas também está sujeito a impactos decorrentes da circulação das máquinas e operários no setor. $\mathrm{O}$ acúmulo de vasilhames é consequência da política de compra da empresa, a qual solicita fornecimento mensal do produto em um único lote com tamanho médio de 350.000 garrafas que visa garantir suprimento durante o período.

Frente a essas constatações, sugeriu-se à diretoria da empresa a redução do tamanho dos lotes junto ao fornecedor e adoção de uma política de abastecimento com revisões semanais. Com a adoção dessas medidas e redução dos lotes para aproximadamente 100.000 garrafas/semana, obteve-se como resultado imediato um ganho de espaço considerável. A circulação de pessoal foi facilitada, além de eliminar o risco decorrente de choques com os pallets de garrafas. Como conseqüência negativa, obteve-se um incremento nos custos de fornecimento de garrafas, decorrente de um maior número de entregas à empresa.

A segunda análise diz respeito as perdas por transporte devido à posição inadequada dos vasilhames estocados [Perda (2)]. Conforme apresentado na Figura 1, os vasilhames eram acomodados a uma distância excessiva do início da linha de engarrafamento. A existência de um muro de separação entre as duas alas impedia a comunicação direta entre os setores de estoque e engarrafamento, fazendo com que os pallets de garrafas fossem conduzidos por empilhadeiras de um pavilhão a outro (circulando toda a linha de engarrafamento). O percurso médio em um único sentido totalizava 120 metros, acarretando perdas por transporte e implicando em risco de danos à estrutura das garrafas.

Propôs-se à empresa a remoção do muro que separava as duas alas e a aproximação do 
estoque em direção ao início da linha. A primeira modificação foi efetivada após comprovar-se que a retirada do muro não prejudicaria a estrutura do prédio. Tais alterações conduziram à imediata elevação da eficiência do processo, visto que as garrafas passaram a ser prontamente dirigidas à lavagem, eliminando a necessidade de transporte por empilhadeira. Paralelamente, eliminou-se o cruzamento das rotas dos vasilhames vazios que deixavam o estoque e as garrafas cheias encaminhadas para a expedição. A Figura 4 ilustra o layout resultante de tais modificações.

A terceira análise diz respeito as perdas devido à grande quantidade de vasilhames cheios aguardando expedição [Perda (3)]. Os estoques de garrafas cheias e vazias apresentavam problemas e características similares: ocupação de grande área, possibilidade de acidentes e recursos ociosos. Propôs-se à diretoria da empresa a redução do tamanho dos lotes a serem engarrafados (seguindo os preceitos de lotes tendendo ao unitário que caracterizam a Produção Enxuta), acionamento da linha no momento de chegada dos pedidos (seguindo a lógica do just-in-time) e liberação mais freqüente dos pedidos concluídos. Tal proposta foi analisada mas não foi aceita, visto que os grandes clientes da empresa (fornecedores de supermercados) fazem questão de adquirir lotes maiores. Tendo em vista que a capacidade de engarrafamento da linha não é grande, faz-se necessário, então, trabalhar com um estoque de segurança.

\subsection{Perdas por quebra de vasilhames durante enchimento e colocação da rolha de fechamento das garrafas}

Os processos de enchimento e colocação da rolha geram dois picos de pressão que podem levar à ruptura da garrafa, caso exista alguma falha ou fissura em sua estrutura. Dados coletados pela empresa apontam um percentual de quebra da ordem de $0,3 \%$ a $0,5 \%$ sobre o total de garrafas processadas. Inspeções são realizadas pelo fabricante das garrafas antes da expedição; entretanto, o transporte por meio rodoviário causa pequenas trincas que não são percebidas por análise visual antes do engarrafamento. Tais trincas fazem com que as garrafas rompam durante o processo de enchimento. Em conseqüência, observam-se perdas de casco, líquido e rolha (essa última em caso de ruptura durante sua colocação), além da parada da linha para limpeza da esteira e máquinas, caracterizando dois tipos de perdas: por fabricação de produtos defeituosos e por espera. Casos mais extremos de ruptura podem arremessar estilhaços de vidro, comprometendo outras garrafas na linha ou até mesmo atingindo operários.

Um procedimento de teste das garrafas foi adotado previamente ao processo de enchimento e colocação da rolha. Neste teste, as garrafas vazias são submetidas a uma pressão equivalente à verificada nos processos em si. O dispositivo de teste é composto por um bico injetor de ar comprimido operado manualmente, conforme ilustrado na Figura 2. Uma cobertura metálica 
envolve a garrafa durante o teste, contendo os estilhaços no evento de ruptura. Em caso de quebra do vasilhame, são evitadas a perda de líquido e da rolha, bem como procedimentos de limpeza e setup.

Figura 2 - Dispositivo de teste para o vasilhame vazio

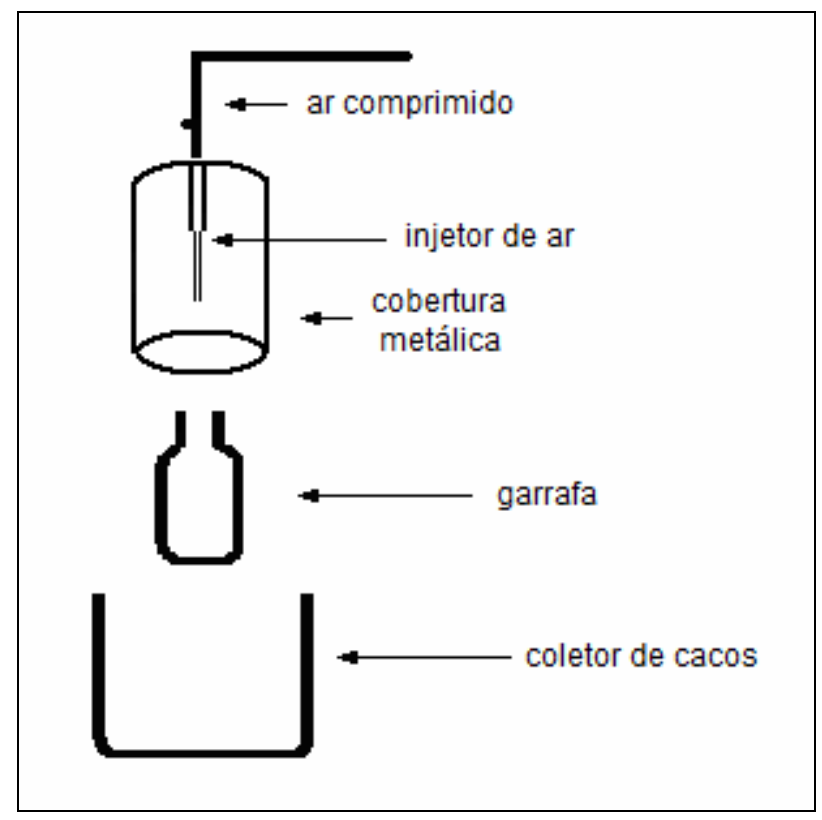

Fonte: Autoria própria (2009)

O dispositivo na Figura 2 foi testado no início da linha de produção. Cada garrafa foi colocada em uma redoma coletora de cacos, injetando-se o ar em seguida. Foram testadas 2500 unidades, das quais 16 quebraram (isto é, $0,64 \%$ das unidades, um valor um pouco mais alto do que aqueles apontados pelos dados históricos disponíveis na empresa). As garrafas aprovadas foram conduzidas ao processo de enchimento e não apresentaram nenhuma anormalidade. Outro aspecto positivo do mecanismo é a não-necessidade do funcionário de inspeção responsável pela parada da linha no caso de ruptura das garrafas nas máquinas de enchimento e colocação de rolha, visto que o dispositivo praticamente elimina a possibilidade de tal ocorrência. O procedimento foi aprovado e um dispositivo de maior capacidade de processamento, estruturalmente semelhante ao dispositivo ilustrado na Figura 2, foi implantado em caráter definitivo na linha.

\subsection{Perda por fabricação de produtos defeituosos no encapsulamento}

Uma cápsula de plástico é colocada sobre a rolha, tendo por função proteger a extremidade da cortiça e agregar valor estético ao produto. Na esteira de engarrafamento da empresa analisada, a 
cápsula (com diâmetro levemente superior ao diâmetro do bico da garrafa) é posicionada manualmente no gargalo da garrafa, a qual passa por uma câmara de aquecimento. Tal câmara é composta por resistências paralelas que forçam o derretimento da cápsula e conferem sua fixação na extremidade da garrafa. Entretanto, a aplicação de calor não se dá de maneira uniforme, fazendo com que partes da cápsula recebam maior radiação e sofram deformações excessivas, resultando no enrugamento de sua base e conseqüente prejuízo estético à garrafa. Nesse caso, de acordo com a conceituação do STP, geram-se perdas por fabricação de produto defeituoso.

A melhoria proposta para minimizar o problema consistiu na instalação de um mecanismo que induz a rotação da garrafa quando esta recebe calor das resistências. O movimento de rotação é obtido através de um cilindro giratório de borracha instalado na parede da câmara de aquecimento. Ao passar pela constrição gerada pelo cilindro, a garrafa sofre uma pequena rotação que acaba por distribuir de forma homogênea a radiação sobre a cápsula. O dispositivo idealizado é apresentado na Figura 3. As dimensões do cilindro de borracha foram definidas em experimentos, na presença de radiação.

Figura 3 - Vista superior do dispositivo rotador da garrafa

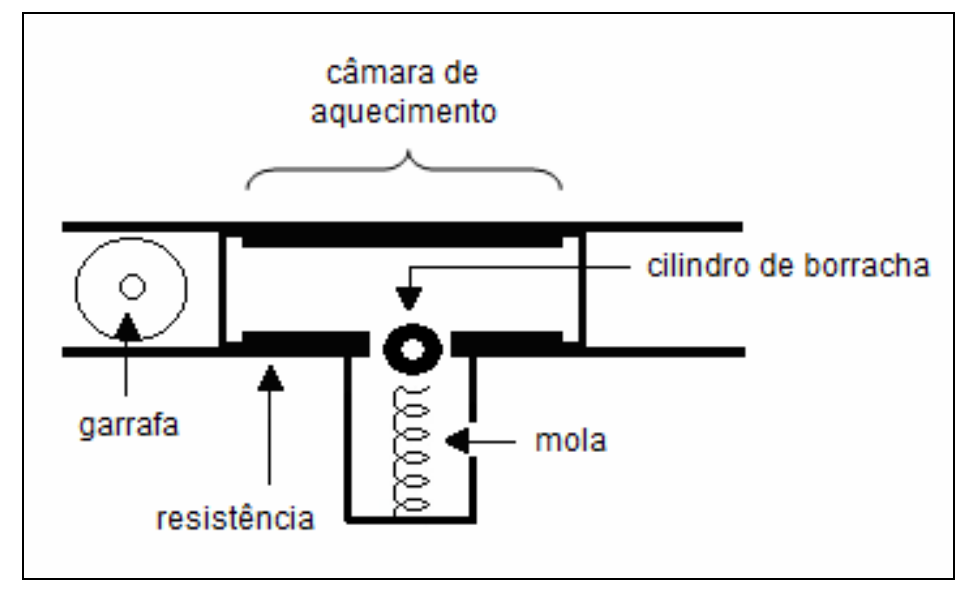

Fonte: Autoria própria (2009)

Conforme mencionado anteriormente, a nova representação da linha de engarrafamento, após implementação das modificações propostas, pode ser visualizada na Figura 4. Ressalta-se a redução do número de operações na linha de produção, se comparado com o cenário inicial, na Figura 1. O layout modificado demanda 6 operadores, representando uma redução de 33\% quando comparado à necessidade de mão-de-obra inicial. 
Figura 4 - Layout da linha de engarrafamento após alterações

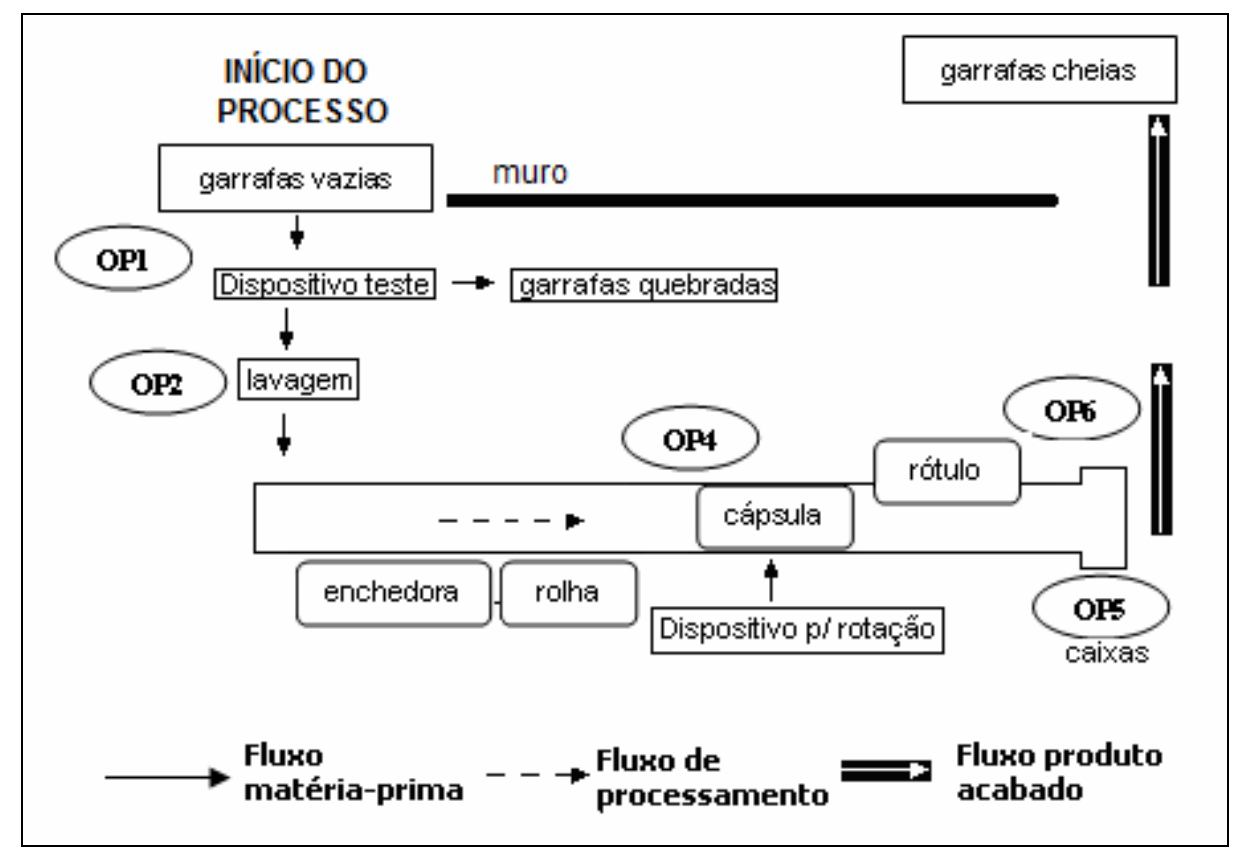

Fonte: Autoria própria (2009)

\section{Conclusões}

O conjunto de conceitos, técnicas e ferramentas que compõem a Produção Enxuta vem encontrando crescente aplicação prática nos setores de serviços e industrial, em particular em segmentos tradicionais (OLIVER et al., 2005). Entretanto, uma análise da literatura especializada sobre o tema revela um pequeno número de publicações enfocando a Produção Enxuta na indústria alimentícia (e.g., SOHAL; EGGLESTONE, 1994), e a ausência de referências a aplicações de suas ferramentas na indústria vinícola.

Este artigo apresenta uma aplicação inédita dos conceitos do Sistema Toyota de Produção (STP) na melhoria do processo produtivo em uma empresa vinícola. Ferramentas oriundas da Engenharia de Produção, como mudança de layout e desenvolvimento de dispositivos anti-falhas, foram implementadas em conjunto com a análise de perdas preconizada pelo STP, em um estudo de caso realizado em uma linha de engarrafamento de vinho.

A utilização do conceito de perdas e de sua categorização de acordo com o Sistema Toyota de Produção (STP) mostrou-se eficiente na detecção e redução/eliminação de perdas na linha de engarrafamento da empresa analisada. A antiga rotina de realização de melhorias priorizava o setor de elaboração de vinhos, deixando de atuar nas demais etapas e elementos do processo que, conforme apresentado, geravam perdas consideráveis. A aplicação dos conceitos do STP conduziu a uma percepção mais completa do processo, facilitando a identificação de pontos passíveis de 
melhoria.

Aspectos relacionados à movimentação de insumos e volume de estoques apresentaram-se como pontos críticos de perda, sobre os quais focaram-se os principais esforços de mudança. Quando as alterações propostas foram implementadas, verificou-se como resultado uma maior flexibilidade da linha, bem como a eliminação de perdas relativas ao material parado e transporte desnecessário do mesmo. Os dispositivos implementados ao longo da linha mostraram-se eficientes, visto que, além de diminuírem o percentual de defeituosos, também viabilizaram o remanejo de operários para outros setores, deixando o processo de engarrafamento mais enxuto, dinâmico e menos oneroso.

Por fim, destaca-se a flexibilidade dos conceitos pertinentes ao STP. Tais conceitos mostraram-se genéricos o suficiente e aplicáveis em um tipo de organização bastante distinta daquelas que motivaram a sua proposição original. Sua aplicação em outros setores, de tal forma, é altamente recomendada.

\begin{abstract}
Important market changes have challenged the Brazilian wine industry. Improvements in product and process quality are vital if Brazilian companies are to compete in a market with increasing volume of high quality imported wines. In such context, losses of any nature in the production process must be reduced or eliminated in order to sustain the competitiveness of the Brazilian wine segment. This paper addresses the use of Lean Manufacturing concepts to improve the production process of a Brazilian wine producer. Through interviews and films, we identified the bottling line as responsible for the majority of production losses. Techniques from Industrial Engineering, such as layout design and error proofing tools, were implemented in that line. The proposed modifications reduced raw material transportation, eliminated losses due to bottle rupture and optimized the number of workers.
\end{abstract}

Keywords: Production losses, Lean manufacturing, Toyota Production System, Wine industry.

\title{
Referências
}

ANDERSON, K. The World's Wine Markets: Globalization at Work. Edward Elgar Publishing, 2004.

ANTUNES Jr., J. A. V. A Lógica das Perdas nos Sistemas de Produção; uma análise crítica. Revista Brasileira de Administração Contemporânea. Rio de Janeiro: ANPAD, v.1, n.7, p.35-371, 1995.

ANTUNES Jr., José Antonio Valle. Em Direção a uma Teoria Geral do Processo na Administração da Produção; uma discussão sobre a possibilidade de unificação da teoria das restrições e da teoria que sustenta a construção dos sistemas de produção com estoque zero. 1998. Tese de Doutorado em Administração, Programa de PósGraduação em Administração, Universidade Federal do Rio Grande do Sul, Porto Alegre, 399p.

BOUlton, R.; SINGleton, V.; BISSON, L; KUNKEE, R. Principles and Practices of Winemaking. New York: Chapman \& Hall, 1996.

GHINATO, P. Elementos para a Compreensão de Princípios Fundamentais do Sistema Toyota de Produção: Autonomação e Zero Defeitos. Porto Alegre, 1994. Dissertação de Mestrado em Engenharia (Produção), Programa de Pós-Graduação em Engenharia de Produção, Escola de Engenharia, Universidade Federal do Rio Grande do Sul. 
GHINATO, P. Sistema Toyota de Produção, mais do que simplesmente just-in-time. Caxias do Sul: EDUCS, 1996. HOPP, W.; SPEARMAN, M. Factory Physics; foundations of manufacturing management. Boston: Irwin/McGraw-Hill, 1996.

JONSSON, A-S.; TRAGARDH, G. Ultrafiltration applications. Desalination, v.77, p. 135-179, 1990.

MANCOZZO, L.; MASTROCOLA, D.; NICOLI, M.C. Chain-breaking and oxygen scavenging properties of wine as affected by some technological procedures. Food Research International, v.31, n. 9, p. 673-678, 1999.

cross ${ }^{\text {ref }}$

NETZEL, M.; STRASS, G.; BITSCH, I.; KONITZ, R.; CHRISTMANN, M.; BITSCH, R. Effect of grape processing on selected antioxidants in red wine. Journal of Food Engineering, v.56, n.2-3, p. 223-22, 2003.

cross ${ }^{\text {ref }}$

OHNO, T. O Sistema Toyota de Produção; Além da produção em larga escala. Porto Alegre: Bookman, 1997.

OLIVER, N.; DELBRIDGE, R.; LOWE, J. Lean Production Practices: International Comparisons in the Auto Components Industry. British Journal of Management, v.7, n. 1, p. S29 - S44, 2005.

cross ${ }^{\text {ref }}$

OREGLIA, F. Enologia Teorico-Practica. Mendonza: Editora Acrilis, 1964.

ORR, S. The role of capacity management in manufacturing strategy: experiences from the Australian wine industry. Technology Analysis \& Strategic Management, v.11, n.1, p. 45-53, 1999. cross ref

POMPELLI, G.; PICK, D. International Investments Motivations of U.S. Wineries. International Food and Agribusiness Management Review, v.2, n.1, p 47-62, 1999.

cross ref

SALAZAR, F.; BRUINJ, J.; SEMINARIO, L.; GUELL, C.; LOPEZ, F. Improvement of wine crossflow microfiltration by a new hybrid process. Journal of Food Engineering, v. 79, n. 4, p. 1329-1336, 2007.

cross ${ }^{\text {ef }}$

SANTO, B. Re-engineering the art of wine making. Electronic Engineering Times, 925, p. 119-121, 1996.

SHINGO, S. A Revolution in Manufacturing; the smed system. Portland : Productivity Press, 1985.

SHINGO, S. O Sistema Toyota de Produção do ponto de vista da Engenharia de Produção. 2 ed., Porto Alegre: Bookmark, 1996a.

SHINGO, S. Sistemas de Produção com Estoque Zero; o sistema Shingo para melhorias contínuas. Porto Alegre: Bookman, 1996b.

SHINGO, S. Zero Quality Control; source inspection and the poka-yoke system. Cambridge: Productivity Press, 1986.

SKOGERSON, K.; DOWNEY, M.; MAZZA, M.; BOULTON, R. Rapid determination of phenolic components in red wines from UV-visible spectra and the method of partial least squares. American Journal of Enology and Viticulture, v. 58, n. 3, p. 318-325, 2007.

SOHAL, A. S.; EGGLESTONE, A. Lean Production: Experiences among Australian organizations. International Journal of Operations \& Production Management, v. 14, n. 11, p. 35-51, 1994.

cross ${ }^{\text {ref }}$

TESFAYE, W.; MORALES, M.L.; GARCIA-PARRILlA, M.C.; TRONCOSO, A.M. Wine: technology, authenticity and quality evaluation. Trends in Food Science and Technology, v.13, n.1, p. 12-21, 2002.

cross ref

VEMHET, A.; CARTALADE, D.; MOUTOUNET, M. Contribution to the understanding of fouling build-up during microfiltration of wine. Journal of Membrane Science, v.211, n.2, p. 357-370, 2003.

cross ref 
VERSARI, A.; BOULTON, R.; PARPINELLO, G. A comparison of analytical methods for measuring the color components of red wines. Food Chemistry, v. 106, n. 1, p. 397-402, 2008.

cross'

WOMACK, J. P.; JONES, D. T.; ROOS, D. A Máquina que Mudou o Mundo. 11.ed. Rio de Janeiro : Campus, 1992.

ZOECKLEIN, B.W.; JASINSKI, Y.; McMAHON, H. Effect of fermentation, aging, and aging sur lie on total and phenol-free Riesling glycosides. Journal of Food Composition and Analysis, v.11, n.3, p. 240-248, 1998.

cross ${ }^{\text {ref }}$

\section{Dados dos autores:}

Nome completo: Michel Jose Anzanello

Filiação institucional: RUTGERS - The State University of New Jersey

Departamento: Industrial and Systems Engineering

Função ou cargo ocupado: Doutorando

Endereço completo para correspondência: 793 Bevier Road, Piscataway, NJ, 08854, USA

Telefones para contato: 7328016404

e-mail: michelja@eden.rutgers.edu

Nome completo: Antônio Sérgio Falcão

Filiação institucional: Universidade Federal do Rio Grande do Sul (UFRGS)

Departamento: Engenharia de Produção

Função ou cargo ocupado: Pesquisador

Endereço completo para correspondência: Avenida Osvaldo Aranha, 99, $5^{\circ}$ andar, Porto Alegre, RS, Brasil, 90035-190

Telefones para contato: (51) 3308-3490

e-mail: asergf@uol.com.br

Nome completo: Flávio Sanson Fogliatto

Filiação institucional: Universidade Federal do Rio Grande do Sul (UFRGS)

Departamento: Engenharia de Produção

Função ou cargo ocupado: Professor Adjunto

Endereço completo para correspondência: Avenida Osvaldo Aranha, 99, $5^{\circ}$ andar, Porto Alegre, RS, Brasil, 90035-190

Telefones para contato: (51) 3308-4294

e-mail:ffogliatto@producao.ufrgs.br

Nome completo: Tiago Pascoal Filomena

Filiação institucional: The George Wahington University

Departamento: Systems Engineering

Função ou cargo ocupado: Doutorando

Endereço completo para correspondência: 8009 Eastern Avenue, apt. 302, MD, 20910, USA

Telefones para contato: 2024608628

e-mail:tiagopf@gwu.edu

Recebido para publicação em: 22/01/2009

Aceito para publicação em: 12/03/2009 